\title{
Assessment of a school-based intervention in eating habits and physical activity in school children: the AVall study
}

\author{
Esteve Llargues, ${ }^{1}$ Rosa Franco, ${ }^{2}$ Assumpta Recasens, ${ }^{1}$ Ana Nadal, ${ }^{2}$ Maria Vila, ${ }^{1}$ \\ Maria José Pérez, ${ }^{3}$ Josep Maria Manresa, ${ }^{4}$ Isabel Recasens, ${ }^{3}$ Gemma Salvador, ${ }^{5}$ \\ Jaume Serra, ${ }^{5}$ Eulàlia Roure, ${ }^{5}$ Conxa Castells ${ }^{5}$
}

${ }^{1}$ Internal Medicine Department, Granollers General Hospital, Granollers, Spain

${ }^{2}$ Public Health Department, Granollers City Council,

Barcelona, Spain

${ }^{3}$ Primary Health Subdivision (PCS) Granollers-Mollet, Catalan Institute of Health, Spain

${ }^{4}$ Primary Healthcare Research Support Unit Metropolitana Nord. IDIAP Jordi Gol. Catalan Institute of Health, Sabadell, Spain

${ }^{5}$ Health Department, Generalitat de Catalunya, Barcelona, Spain

\section{Correspondence to}

Dr Esteve Llargués, Internal Medicine Department Granollers General Hospital, Av Francesc Ribes s/n, 08402 Granollers, Spain ellargues@fhag.es

Accepted 9 February 2011 Published Online First 12 March 2011

\section{(2) UN OCKKA}

This paper is freely available online under the BMJ Journals unlocked scheme, see http:// jech.bmi.com/site/about/ unlocked.xhtml

\section{ABSTRACT}

Background Obesity has become a global public health problem, which also affects children. It has been proposed that the educational interventions during childhood could be a key strategy in the prevention of obesity.

Objective To evaluate the efficacy of an intervention on food habits and physical activity in school children. Methods A 2-year cluster-randomised prospective study with two parallel arms was used to evaluate an intervention programme in children in their first year of primary schooling (5-6 years of age) in schools in the city of Granollers. The intervention consisted of the promotion of healthy eating habits and physical activity by means of the educational methodology Investigation, Vision, Action and Change (IVAC). At the beginning and at the end of the study (2006 and 2008) the weight and height of each child was measured in situ, while the families were given a self-report physical activity questionnaire and the Krece Plus quick test.

Results Two years after the beginning of the study, the body mass index of the children in the control group was $0.89 \mathrm{~kg} / \mathrm{m}^{2}$ higher than that of the intervention schools. The intervention reduced by $62 \%$ the prevalence of overweight children. Similarly, the proportion of children that ate a second piece of fruit and took part in an after-school physical activity increased in the intervention group. In the control group, the weekly consumption of fish was reduced.

Conclusions The educational intervention in healthy eating habits and physical activity in the school could contribute to lessen the current increase in child obesity.

\section{INTRODUCTION}

Obesity has become a global public health problem affecting adults as well as children and teenagers. ${ }^{1}$ Childhood obesity is considered a health risk and it reduces life expectancy. ${ }^{2}$

The increase in the prevalence of obesity can be attributed to the changes in lifestyle of the past decades, which entails an imbalance between the intake and the expenditure of energy. It is becoming more evident that the environment is the main 'obesogenic' factor. Thus, in order to fight obesity a number of measures involving the family, school, urban planning, health services, transport systems, the media and food industry are required. ${ }^{3}$

Following WHO guidelines, the Health Ministry ${ }^{4}$ plans multisectorial and intersectorial public health strategies for nutrition, physical activity and prevention of obesity. In Catalonia, the Health Department of the Generalitat proposes the Integral Plan for Health Promotion through Physical Activity and Healthy Nutrition, which aims at the promotion of healthy habits in the population ${ }^{5}$ through interventions in schools, health services, community and working environments. Projects such as the PERSEO programme, ${ }^{6}$ Shape-up, ${ }^{7}$ the THAO project and the EDAL study ${ }^{8}$ are currently taking place in Spain.

It has been shown that the treatment of obesity in adult life through changes in lifestyle is extremely difficult. ${ }^{9}$ Therefore, educational interventions toward food and physical activity during childhood could be a key strategy in the prevention of obesity. ${ }^{9}$

Many interventions to modify food habits and to promote physical activity in order to reduce the prevalence of obesity have been carried out in the school setting. They consist mainly of observational studies in a wide age-range or in school children over 10 years of age, with a short observation period, and the body mass index (BMI) results have not always been positive. ${ }^{10}$ Even though some of the results are contradictory, the biggest impact in the BMI has been obtained through curriculum-linked interventions ${ }^{11}$ that deal with food habits and physical activity simultaneously in teenagers. ${ }^{10} 1213$

There are few studies in school children under 7 years of age and, in most, the intervention has proved ineffective. ${ }^{10} 111314$ However, food habits are acquired at an early age and the diversity of foods introduced at a young stage is a predictive factor of the variety of food in adult life. ${ }^{15}$

The aim of this study was to evaluate the effect of an intervention that modified food and physical activity habits on the progression of BMI in a population of school children using Research, Vision, Action and Change (IVAC) methodology.

\section{METHODS}

\section{Population}

Granollers is a town of 59000 inhabitants with 16 primary schools (10 public or local schools that are fully paid by the government, 6 semi-private schools that receive some money from the government and 0 private schools that are family fully paid). The 16 schools of the city were randomly distributed to the intervention group or to the control group. All the children born in 2000 
who attended any of the schools in Granollers were eligible to participate. The exclusion criteria were school children who need a special diet for a metabolic or digestive disorder, physical activity incapacity, no family acceptance or attendance to school.

The project was approved by the Clinical Research Ethical Committee of Granollers General Hospital and had the support of the Education and Health Departments of the Catalan government and of all headmasters/headmistresses of the schools involved. In September 2008, the schools provided the names, sex and date of birth of the children, and the informed consent of the families to participate in the study was obtained.

\section{Design}

We used a 2-year cluster-randomised prospective study with two parallel arms. The 16 schools were grouped into strata, depending on whether they were public or not, and they had the same number of classes of first primary course. Each school in the groups was randomly assigned to the control or intervention group. For two consecutive years, an intervention was carried out on all the school children born in the year 2000 of the intervention schools: five public and three semi-private. The rest of the primary schools of the city were used as controls.

At the beginning and at the end of the study, October 2006 and October 2008, each family received the quick test Krece Plus to evaluate the food habits of the child. ${ }^{16}$ Information on the following habits was collected: eating at school, walking to school and time to walk to school, exercising after school hours, going to a playground or walking after school, daily hours of television, video or DVD, and physical activity during weekends. The height, weight and level of education of the parents were recorded together with other sociodemographic data.

The weight and height of the children were obtained at their schools during September and October 2006 and 2008 by two specifically trained nurses.

\section{Intervention}

At the beginning of the project, an information session with the parents of the school children in the intervention group was organised. The educational methodology IVAC, ${ }^{17}$ based on the principle that the school children are actors able to operate over their environment, was used. The children investigate and reflect on how the environment determines their health and lifestyle, while the teacher assists them in developing skills to change these conditions. This educational method allows the inclusion of activities related to healthy food habits and physical activity in any subject of the curriculum.

At the beginning of the study, a group of educators specialised in community projects (PAU Education) carried out training sessions on this methodology for the teachers of the intervention group. Over the 2-year period, six meetings with the research team, the teachers and the educators took place in order to monitor the activities accomplished and to plan subsequent actions. Every classroom used $3 \mathrm{~h}$ a week to develop activities related to health food habits and/or physical activity. This time was part of regular classes-math, science, language, knowledge of the environment-developing posters, food tables, games, crafts, cooking workshops and promotion of games in the playground. Every month healthy recipes were distributed to the families for children to carry out at home. All these activities were reported at the meetings with the research team.

The intervention group of each school was given educational material on healthy food, as well as educational material on games to promote physical activity during break time. Each school was also offered the necessary equipment for these games.

During the study period, each family in the intervention group received monthly recipes for a balanced diet taking into account traditional food habits. The families also received a guide of the local areas and paths to exercise during weekends and books about balanced eating were recommended.

\section{Variables of the study}

The main outcome of the study was the difference in BMI progression in the intervention and the control group. Secondary outcomes measured in this study were changes in eating habits and in physical activity.

The weight of the children was obtained with the children barefoot and dressed in light clothes. A portable digital scale with a precision of $\pm 100 \mathrm{~g}$ (Oregon model BWR101, Oregon Scientific, Hong Kong) was used. The height was obtained using portable body measuring tape (MZ10017) with a precision of $\pm 0.1 \mathrm{~cm}$. The children were standing barefoot, their back midline against the measuring tape, the line of sight parallel to the floor and measured to the closest millimetre. The BMI was derived from the measured weight and height (weight in $\mathrm{kg} /$ height in $\mathrm{m}^{2}$ ).

The children's food habits were assessed by means of a food frequency questionnaire and the Krece Plus test. The time it took to walk to school was categorised in to less than $10 \mathrm{~min}$, 10-20 min and more than $20 \mathrm{~min}$. The time spent watching television, videos or DVD was categorised in to $1-2 \mathrm{~h}$ per day and more than $2 \mathrm{~h}$ per day. Physical activity after school and physical activity during the weekend was categorised as yes, no and sometimes.

BMI was categorised as underweight, healthy weight, overweight and obese using the cut-off criteria proposed by the International Obesity Task Force. ${ }^{18}$ Age was categorised using the cut-off points proposed in the reference tables $(6,6.5$ and 7 years of age). BMI was calculated based on the age and sex of each child.

Following Garrow's criteria, BMI was used to classify the weight status of the parents. The level of education of the parents was classified as 'does not read or write', 'primary education', 'secondary education' and 'university'.

\section{Sample size}

Accepting an $\alpha$ risk of 0.05 and a $\beta$ risk of 0.20 in a two-sided test, 92 subjects are necessary in the control group and 92 in the intervention group to recognise a statistically significant interaction with a minimum difference greater than or equal to 0.2 units. The common SD is assumed to be 2.5 and the correlation coefficient between the initial and final measurement as 0.8 . It has been anticipated a drop-out rate of 0.1 .

Using an intracluster correlation coefficient of $0.05,{ }^{19-21}$ and based on an average cluster size of 30 students by school, the design effect is 2.45. Therefore, 226 school children for each group were needed. The accessible school population is Granollers is about 500 students so the study population is higher than necessary. The sample size was calculated using the Study Size 2.0 programme for Windows.

\section{Statistical analysis}

Qualitative variables are described in absolute and relative frequencies (percentages). Continuous variables are described as mean and SD.

To compare qualitative variables, Pearson's $\chi^{2}$, Fisher's exact test or $\chi^{2}$ for trend and the McNemar test for paired proportions were used. To compare quantitative variables, the Student $t$ test for independent data was used. 
Analysis of variance for repeated measures based on a multivariate generalised linear model (always adjusted by school) was used to assess the effect of the intervention on the children's BMI progression taking into account any variables that modified the effect observed during the intervention (interaction effect); primarily those that were unevenly distributed between the control and intervention groups at baseline. This procedure is equivalent to multi-level analysis in cluster designs. ${ }^{22}$

To evaluate the effect of the intervention on height, an analysis of variance for repeated measures as in the analysis of BMI was used. The progression of height among the intervention and control groups was compared and the model was adjusted for the mother's and the father's height. For a better visualisation of the effect, it was categorised in tertiles and the analysis was repeated.

To explain which variables accounted better for the effect observed in the intervention, a multivariate linear regression analysis was carried out. The dependent variable was the increase of the BMI compared to the baseline value, the independent explanatory variables all those that in some of the association analyses showed a significance level $(p \leq 0.125)$. From a model saturated with all these variables, a simplified model that could better explain the increase of the BMI in both groups was used.

Statistical analyses were carried out using SPSS 13.0.

\section{RESULTS}

Of the 704 children enrolled, 598 (84.9\%) children agreed to participate in the study. Eighty-nine children were excluded because of missing administrative data, absence in the school to perform anthropometric measurements or transfer to another school during the study. Complete data on anthropometric variables were obtained in 509 of the 704 children (72.3\%), 237 $(78.8 \%)$ in the control group and $272(72.7 \%)$ in the intervention group. The quick test Krece Plus and the physical activity questionnaire were completely filled in by $156(51.8 \%)$ children in the control group and $216(57.7 \%)$ in the intervention group. The percentage of girls was $45.6 \%$ and $45.3 \%$, respectively (table 1 ).

At the beginning of the study, the mean age of both groups was $6.03 \pm 0.3$ years. The BMI of the children in both control and intervention groups was similar $\left(16.6 \pm 2.5\right.$ and $16.8 \pm 2.0 \mathrm{~kg} / \mathrm{m}^{2}$, respectively). The girls' BMI in the control group was lower than in the intervention group $\left(16.2 \pm 2.8 \mathrm{~kg} / \mathrm{m}^{2}\right.$ vs $17.0 \pm 2.6 \mathrm{~kg} / \mathrm{m}^{2}$, respectively, $\mathrm{p}=0.034)$. The variables immigrant, walking to school (table 1), time to walk to school, physical activity after school hours, time spent watching television, videos, DVD and similar activities, mean BMI and level of education of the parents were comparable in both groups.

The variables breakfast before going to school, quality of the breakfast (cereals or derivatives, milk or dairy products and fruit were considered a proper breakfast), intake of five portions a day of fruit and vegetables, eating nuts twice or more per week, consumption of pastries as a mid-afternoon snack three or more times per week and having fizzy drinks three or more times weekly were comparable in both groups. However, a higher proportion of children from the intervention group ate at school (table 1).

Table 2 shows the initial characteristics of both groups in relation to the Krece Plus questionnaire. Some children in the control group ate fish more frequently than in the intervention group.

At the end of the study period of 2 years, the intervention group presented a lower increase of the BMI $\left(0.85 \mathrm{vs} 1.74 \mathrm{~kg} / \mathrm{m}^{2}\right.$, $\mathrm{p}<0.001$ ) (table 3 ). The prevalence of overweight and obese variable the intervention or control group, and the adjustment or

Table 1 Baseline characteristics of both groups

\begin{tabular}{|c|c|c|c|}
\hline & $\begin{array}{l}\text { Control group } \\
(\mathrm{N}=237)\end{array}$ & $\begin{array}{l}\text { Intervention group } \\
(\mathrm{N}=\mathbf{2 7 2})\end{array}$ & p Value \\
\hline Girls & $108(45.6 \%)$ & $126(46.3 \%)$ & NS \\
\hline BMI & $16.4(2.7)$ & $16.9(2.3)$ & 0.024 \\
\hline Height & $1.21(0.06)$ & $1.19(0.06)$ & NS \\
\hline Walks to school & $112(47.3 \%)$ & $139(51.1 \%)$ & NS \\
\hline \multicolumn{4}{|l|}{ Time to walk to school } \\
\hline No answer & 1 & 1 & \\
\hline Less than $10 \mathrm{~min}$ & $58(52.3 \%)$ & $65(47.1 \%)$ & NS \\
\hline $10-20 \mathrm{~min}$ & $42(37.8 \%)$ & $51(37.0 \%)$ & NS \\
\hline$>20 \min$ & $11(9.9 \%)$ & $22(15.9 \%)$ & NS \\
\hline Eats at school & $65(27.4 \%)$ & $120(44.2 \%)$ & 0.001 \\
\hline Exercises & $114(48.1 \%)$ & $142(52.2 \%)$ & NS \\
\hline Father's height & $1.74(0.07)$ & $1.75(0.07)$ & NS \\
\hline Mother's height & $1.61(0.07)$ & $1.62(0.07)$ & NS \\
\hline Immigrant & $49(20.7 \%)$ & 47 (17.3\%) & NS \\
\hline Reported answer & $\begin{array}{l}\text { Control group } \\
N=159\end{array}$ & $\begin{array}{l}\text { Intervention group } \\
\mathrm{N}=\mathbf{2 1 6}\end{array}$ & p Value \\
\hline Hours of television per day & & & NS \\
\hline$<2 \mathrm{~h} /$ day & $116(73.0 \%)$ & $172(79.6 \%)$ & \\
\hline$>2 \mathrm{~h} /$ day & $43(27.0 \%)$ & $44(20.4 \%)$ & \\
\hline BMI father & $26.1(3.1)$ & $26.1(3.7)$ & NS \\
\hline BMI mother & $23.4(3.6)$ & $23.3(3.7)$ & NS \\
\hline Level of education father & & & 0.055 \\
\hline Does not read and write & $4(2.5 \%)$ & $7(3.3 \%)$ & \\
\hline Primary & $48(30.8 \%)$ & $37(17.4 \%)$ & \\
\hline Secondary & $70(44.9 \%)$ & $115(54.0 \%)$ & \\
\hline University & $34(21.8 \%)$ & $54(25.3 \%)$ & \\
\hline Level of education mother & & & NS \\
\hline Does not read and write & $2(1.3 \%)$ & $6(2.8 \%)$ & \\
\hline Primary & $43(27.2 \%)$ & $38(17.4 \%)$ & \\
\hline Secondary & $75(47.5 \%)$ & 109 (49.8\%) & \\
\hline University & $38(24.0 \%)$ & $66(30.1 \%)$ & \\
\hline
\end{tabular}

BMI, body mass index; NS, not significant.

children increased by $8.2 \%$ and $2.6 \%$ in the control group, and by $4.8 \%$ and $-0.7 \%$ in the intervention group (table 3 ); thus, the total prevalence of overweight children increased by $10.8 \%$ in the control group and by $4 \%$ in the intervention group.

Table 2 Baseline results of the Krece Plus test

\begin{tabular}{|c|c|c|c|}
\hline & $\begin{array}{l}\text { Control } \\
\text { group } \\
(\mathrm{N}=156)\end{array}$ & $\begin{array}{l}\text { Intervention } \\
\text { group } \\
(\mathrm{N}=\mathbf{2 1 6})\end{array}$ & p Value \\
\hline Does not have breakfast & $3(1.9 \%)$ & $5(2.3 \%)$ & NS \\
\hline $\begin{array}{l}\text { Has a dairy product for breakfast (milk, } \\
\text { yogurt, etc) }\end{array}$ & $148(94.9 \%)$ & $204(94.4 \%)$ & NS \\
\hline Eats cereals or derivative for breakfast & $90(58.1 \%)$ & $138(63.3 \%)$ & NS \\
\hline Eats manufactured pastries for breakfast & $19(12.3 \%)$ & 18 (8.3\%) & NS \\
\hline Eats fruit or juice every day & $126(80.8 \%)$ & $175(81.0 \%)$ & NS \\
\hline Eats a second fruit every day & $52(33.3 \%)$ & $74(34.3 \%)$ & NS \\
\hline Has a second dairy product during the day & $113(72.4 \%)$ & $153(70.80 \%)$ & NS \\
\hline Eats raw or cooked vegetables once a day & $109(69.9 \%)$ & $158(73.1 \%)$ & NS \\
\hline Eats vegetables more than once a day & $42(26.9 \%)$ & $64(29.6 \%)$ & NS \\
\hline Eats fish regularly ( $>2$ times per week) & $132(84.6 \%)$ & $159(73.6 \%)$ & 0.011 \\
\hline $\begin{array}{l}\text { Eats once or more weekly in a fast food } \\
\text { restaurant }\end{array}$ & $2(1.3 \%)$ & $6(2.8 \%)$ & NS \\
\hline $\begin{array}{l}\text { Likes to eat legumes more than twice } \\
\text { a week }\end{array}$ & $115(73.7 \%)$ & $156(72.2 \%)$ & NS \\
\hline Eats sweets several times a day & $8(5.1 \%)$ & $15(6.9 \%)$ & NS \\
\hline $\begin{array}{l}\text { Eats pasta or rice almost daily } \\
(\geq 5 \text { per week) }\end{array}$ & $77(49.4 \%)$ & $92(42.6 \%)$ & NS \\
\hline Regular consumption of olive oil & $151(96.8 \%)$ & $204(94.4 \%)$ & NS \\
\hline
\end{tabular}


Table 3 Progression of weight status

\begin{tabular}{|c|c|c|c|c|}
\hline & \multicolumn{2}{|l|}{ Control $(n=236)$} & \multicolumn{2}{|c|}{ Intervention $(n=272)$} \\
\hline & 2006 & 2008 & 2006 & 2008 \\
\hline $\mathrm{BMI}^{*}$ & 16.5 (16.7 to 17.5$)$ & $18.3(17.9$ to 18.7$)$ & 17.1 (16.7 to 17.5$)$ & $17.9(17.4$ to 18.4$)$ \\
\hline \multicolumn{5}{|l|}{ Weight status } \\
\hline Normal weight & $176(75.2 \%)$ & $150(64.4 \%)$ & $190(70.1 \%)$ & $179(66.0 \%)$ \\
\hline Overweight & $39(16.7 \%)$ & $58(24.9 \%)$ & $55(20.3 \%)$ & $68(25.1 \%)$ \\
\hline Obesity & $19(8.1 \%)$ & $25(10.7 \%)$ & $26(9.6 \%)$ & $24(8.9 \%)$ \\
\hline Overweight & $58(24.8 \%)$ & $83(35.6 \%)$ & $81(29.9 \%)$ & $92(34.0 \%)$ \\
\hline
\end{tabular}

In the intervention group, there was an increase in the daily intake of a second fruit and in the after school physical activity (table 4), whereas fish consumption decreased in the control group. Both in the control and intervention groups, some children stopped walking to school (13.8\% vs $18.3 \%$, respectively) and eating at school $(14.5 \%$ vs $17.9 \%$, respectively). In the intervention group, there was a non-significant increase in nut intake $(\mathrm{p}=0.056)$ and also a slight reduction of daily time devoted to sedentary activities ( $p=0.061)$.

In mothers with only primary schooling or less, no difference was observed in the BMI progression between the intervention and control groups, whereas in mothers with secondary or university education, the increase in the BMI was lower in the intervention group $(\mathrm{p}=0.018)$.

Table 4 Progression of healthy habits 2 years after the beginning of the intervention

\begin{tabular}{|c|c|c|c|c|c|}
\hline \multirow[b]{2}{*}{ Concept } & \multirow[b]{2}{*}{ Group } & \multicolumn{3}{|c|}{ Progression $2006 \rightarrow 2008$} & \multirow[b]{2}{*}{ p Value } \\
\hline & & No changes & No $\rightarrow$ Yes & Yes $\rightarrow$ No & \\
\hline \multirow[t]{2}{*}{ Eats fruit or juice daily } & Control & $122(80.0 \%)$ & 10 (7.1\%) & 18 (12.9\%) & 0.185 \\
\hline & Intervention & 160 (84.2\%) & $18(9.5 \%)$ & $12(6.3 \%)$ & 0.362 \\
\hline \multirow[t]{2}{*}{ Eats a second fruit } & Control & $108(77.1 \%)$ & $14(10.0 \%)$ & $18(12.9 \%)$ & 0.597 \\
\hline & Intervention & $134(70.6 \%)$ & $39(20.5 \%)$ & 17 (8.9\%) & 0.005 \\
\hline \multirow[t]{2}{*}{ Eats vegetables daily } & Control & $114(81.4 \%)$ & $12(8.6 \%)$ & $14(10.0 \%)$ & 0.845 \\
\hline & Intervention & 139 (73.1\%) & $28(14.7 \%)$ & $23(12.1 \%)$ & 0.576 \\
\hline \multirow[t]{2}{*}{ Eats vegetables more than once daily } & Control & $108(77.1 \%)$ & $19(13.6 \%)$ & $13(9.3 \%)$ & 0.377 \\
\hline & Intervention & $137(72.1 \%)$ & $31(16.2 \%)$ & $22(11.6 \%)$ & 0.272 \\
\hline \multirow[t]{2}{*}{ Eats fish $\geq 2$ times per week } & Control & $101(71.6 \%)$ & $12(8.6 \%)$ & $27(19.3 \%)$ & 0.024 \\
\hline & Intervention & $151(79.5 \%)$ & $24(12.6 \%)$ & $15(7.9 \%)$ & 0.200 \\
\hline \multirow{2}{*}{$\begin{array}{l}\text { Eats once or more weekly in a fast } \\
\text { food restaurant }\end{array}$} & Control & $138(98.6 \%)$ & $1(0.7 \%)$ & $1(0.7 \%)$ & 1.000 \\
\hline & Intervention & $183(96.3 \%)$ & $4(2.1 \%)$ & $3(1.6 \%)$ & 1.000 \\
\hline \multirow[t]{2}{*}{ Eats legumes $\geq 2$ times per week } & Control & $103(73.5 \%)$ & $21(15 \%)$ & $16(11.4 \%)$ & 0.511 \\
\hline & Intervention & $144(75.8 \%)$ & $21(11.1 \%)$ & $25(13.2 \%)$ & 0.659 \\
\hline \multirow{2}{*}{$\begin{array}{l}\text { Eats pasta or rice almost daily } \\
(\geq 5 \text { per week) }\end{array}$} & Control & $104(74.3 \%)$ & $16(11.4 \%)$ & $20(14.3 \%)$ & 0.618 \\
\hline & Intervention & $135(71.0 \%)$ & $32(16.8 \%)$ & $23(12.1 \%)$ & 0.281 \\
\hline \multirow{2}{*}{$\begin{array}{l}\text { Eats pastries more than } 3 \text { times } \\
\text { per week as a mid-afternoon snack }\end{array}$} & Control & $119(85.0 \%)$ & $6(4.3 \%)$ & $15(10.7 \%)$ & 0.078 \\
\hline & Intervention & $161(84.7 \%)$ & $15(7.9 \%)$ & $14(7.4 \%)$ & 1.000 \\
\hline \multirow[t]{2}{*}{ Eats nuts $\geq 2$ times per week } & Control & $100(71.4 \%)$ & $23(16.4 \%)$ & $17(12.1 \%)$ & 0.430 \\
\hline & Intervention & $128(67.4 \%)$ & $39(20.5 \%)$ & $23(12.1 \%)$ & 0.056 \\
\hline \multirow[t]{2}{*}{ Has milk or dairy products daily } & Control & $132(94.2 \%)$ & $5(3.6 \%)$ & $3(2.1 \%)$ & 0.727 \\
\hline & Intervention & $175(92.1 \%)$ & $6(3.2 \%)$ & $9(4.7 \%)$ & 0.607 \\
\hline \multirow[t]{2}{*}{ Eats sweets several times a day } & Control & $132(94.3 \%)$ & $3(2.1 \%)$ & $5(3.6 \%)$ & 0.727 \\
\hline & Intervention & $178(93.7 \%)$ & $6(3.2 \%)$ & $6(3.2 \%)$ & 1.000 \\
\hline \multirow[t]{2}{*}{3 or more fizzy drinks per week } & Control & $125(89.2 \%)$ & $4(2.9 \%)$ & $11(7.9 \%)$ & 0.118 \\
\hline & Intervention & $167(87.9 \%)$ & $11(5.8 \%)$ & $12(6.3 \%)$ & 1.000 \\
\hline \multirow[t]{2}{*}{ Eats at school } & Control & $128(80.5 \%)$ & 8 (5.0\%) & $23(14.5 \%)$ & 0.011 \\
\hline & Intervention & $168(78.1 \%)$ & $11(5.0 \%)$ & 39 (17.9\%) & $<0.001$ \\
\hline \multirow[t]{2}{*}{ Walks to school } & Control & $129(81.1 \%)$ & $8(5.0 \%)$ & $22(13.8 \%)$ & 0.016 \\
\hline & Intervention & $160(73.4 \%)$ & $18(8.3 \%)$ & $40(18.3 \%)$ & 0.005 \\
\hline \multirow[t]{2}{*}{ Exercises } & Control & $109(74.2 \%)$ & $16(10.9 \%)$ & $22(15.0 \%)$ & 1.000 \\
\hline & Intervention & $146(76.4 \%)$ & $30(15.7 \%)$ & $15(7.9 \%)$ & 0.036 \\
\hline \multirow[t]{2}{*}{ TV hours } & Control & $109(75.7 \%)$ & $12(8.3 \%)$ & $23(16.0 \%)$ & 0.090 \\
\hline & Intervention & $155(84.3 \%)$ & $9(4.9 \%)$ & $20(10.9 \%)$ & 0.061 \\
\hline \multirow[t]{2}{*}{ Overweight } & Control & $193(82.9 \%)$ & $33(14.2 \%)$ & $7(3.0 \%)$ & 0.001 \\
\hline & Intervention & $236(87.1 \%)$ & $23(8.5 \%)$ & $12(4.4 \%)$ & 0.090 \\
\hline \multirow[t]{2}{*}{ Proper breakfast } & Control & $143(93.5 \%)$ & 8 (5.2\%) & $2(1.3 \%)$ & 0.109 \\
\hline & Intervention & $196(92.0 \%)$ & $11(5.2 \%)$ & $6(2.8 \%)$ & 0.332 \\
\hline \multirow[t]{2}{*}{ 5-a-day } & Control & $124(95.2 \%)$ & $6(4.5 \%)$ & $3(2.5 \%)$ & 0.508 \\
\hline & Intervention & 62 (92.5\%) & $7(4 \%)$ & $6(3.4 \%)$ & 1.000 \\
\hline
\end{tabular}


Table 5 Multiple linear regression analysis (dependent variable: increase of body mass index after 2 years)

\begin{tabular}{lrccr}
\hline & & \multicolumn{2}{c}{$\mathbf{9 5 \%} \mathbf{C l}$} & \\
\cline { 3 - 4 } Variable & $\boldsymbol{\beta}$ & Lower limit & Upper limit & p Value \\
\hline Constant & 1.721 & 1.379 & -2.063 & $<0.001$ \\
Intervention & -0.962 & -1.342 & -0.582 & $<0.001$ \\
Eats at school & -0.419 & -0.790 & -0.049 & 0.027 \\
Obese mother & 0.990 & 0.121 & 1.859 & 0.026 \\
School & -0.004 & -0.039 & 0.031 & 0.814 \\
\hline
\end{tabular}

The final model (adjusted by school) was developed from an initial model saturated with the following variables: 'eats at school (visit 2)', 'obese mother', 'obese father', 'father's level of education', 'mother's level of education', 'immigrant', 'more than $1 \mathrm{~h}$ of television per day'. All variables reported in 152 school children in control and 199 in intervention group.

The results obtained after the multivariate linear regression analysis including all the variables show that maternal obesity and eating at school were the variables that had an impact on the observed effect of the intervention on BMI always adjusted by school (table 5). Once adjusted by eating at school and obesity of the mother, the effect of the intervention decreases the BMI by $0.872 \mathrm{~kg} / \mathrm{m}^{2}$. Eating at school decreases the BMI by $0.454 \mathrm{~kg} / \mathrm{m}^{2}$ and having an obese mother increases it by $1.086 \mathrm{~kg} / \mathrm{m}^{2}$ (table 5). The school was not significant in the multivariate analysis, but was maintained to obtain the effect of the intervention adjusting for the possible cluster effect.

The height of the children at the beginning and end of the study was different in the control and intervention groups. At baseline, children in the control group were $1.3 \mathrm{~cm}$ taller than children in the intervention group, whereas 2 years later the children in the intervention group measured $0.7 \mathrm{~cm}$ more (table 6). No significant differences were found in the mother's or father's height between both groups.

\section{DISCUSSION}

This is the first study in our setting that analyses the effectiveness of an educational intervention on eating habits and physical activity in a group of 6-year-old school children.

The IVAC methodology was chosen to prevent overloading the schools with additional tasks. This method requires only the training of the teachers and does not affect the teaching programmes. An extracurricular intervention that relied on the collaboration of the school and the family was designed.

Few studies in other countries have evaluated the effect of an extracurricular educational intervention on healthy habits to prevent child obesity. The FiKid ${ }^{23}$ study, a programme of afterschool physical activity that lasted a year, concluded that participation in a physical activity programme was associated with a decrease in body fat but it did not modify the BMI. The APPLE project, an extracurricular programme to promote healthy eating habits and physical activity during 2 years, showed that the BMI increased less in the intervention group, although the prevalence of overweight was similar in both groups. ${ }^{24}$ The study in Cuenca lasting a school year in children at their 4 th and 5 th years of primary schooling showed a reduction in adiposity and an improvement in the lipid profile. ${ }^{25}$

In our study, the intervention managed to reduce the progression of the BMI by $0.89 \mathrm{~kg} / \mathrm{m}^{2}$ so that the incidence of overweight decreased by $62 \%$ at the end of the study. Although the BMI at the beginning of the project was different between the intervention and control groups, this did not influence the efficacy of the intervention. The lower increase in BMI in the intervention group is consistent with the changes in eating habits and physical activity.

In the intervention group an increase in the intake of a second piece of fruit and in physical activity was observed. Other positive changes that were slightly non-significant, such as an increase in the consumption of nuts and a reduction in the daily hours spent in sedentary activities such as watching television, were observed. The increase in the intake of fruit and not of vegetables may be attributable to the children's' preference of fruit over vegetables at this age. ${ }^{15}$

The reduction in BMI measurement over time may be attributed to the intervention. When each of the components were analysed separately-namely eating habits, physical activity, reduction in sedentary occupations - their effectiveness decreased. However, the synergistic effect of every small change is considered to have contributed to these results. In that respect, the American Society for Nutrition advocates for the incentivisation of small changes in lifestyle so that minor but easier improvements in eating habits will contribute to a healthier weight of the population in the long term. ${ }^{9}$

Obesity in the mother and eating at school were the variables influencing the observed effect of the intervention on the BMI. This observation coincides with the results published in the KOPS study, carried out in school children followed-up during 4 years, ${ }^{26}$ which shows that the intervention was not effective in the case of maternal obesity and/or a parental low educational level. The lack of effectiveness of the interventions in this group of school children underlines the need for specific strategies aimed at this segment of the population.

In the current study, the intervention was equally effective in immigrants. This finding could be explained by the low number of immigrants and the great ethnic diversity among them. Interestingly, there was a lower increase in the BMI of the children eating at school. The city council's public health department has checked the school menus since 1993. This would support the theory that the eating habits introduced from early childhood strengthen the effect of the intervention to contain excess weight. ${ }^{15}$ The increase in height was larger in the intervention group. Height is genetically determined. ${ }^{27}$ However, there were no differences in the height of parents between the groups. The difference in height could be explained by the intervention as both the quality of food and nutrients and the contents of the diet were improved. ${ }^{27} 28$

Table 6 Height of children and parents

\begin{tabular}{lllll}
\hline Height of children $(\mathbf{c m})$ & Control $(\mathbf{n}=\mathbf{2 3 7})$ & Intervention $(\mathbf{n}=\mathbf{2 7 2})$ & Total & p Value \\
\hline 2006 & $120.8(120.1$ to 121.7$)$ & $118.4(117.5$ to 119.3$)$ & $120.2(119.6$ to 120.9$)$ & $<0.001$ \\
2008 & $130.9(130.12$ to 131.8$)$ & $132.0(131.0$ to 133.0) & $131.2(130.5$ to 131.9$)$ & - \\
& Control $(\mathrm{n}=144)$ & Intervention $(\mathrm{n}=208)$ & Total & $\mathrm{p}$ Value \\
Height of father $(\mathrm{cm})$ & $1.74(0.07)$ & $1.75(0.07)$ & $1.75(0.07)$ & NS \\
& Control $(\mathrm{n}=153)$ & Intervention $(\mathrm{n}=214)$ & Total & $\mathrm{p} \dagger$ \\
Height of mother $(\mathrm{cm})$ & $1.61(0.07)$ & $1.62(0.07)$ & $1.61(0.07)$ & NS
\end{tabular}

*Estimated marginal means and $95 \% \mathrm{Cl}$ obtained by multivariate analysis of variance for repeated measures (adjusted for school): $\mathrm{p}<0.001$. (Outcome effect: interaction between the height of children progression over 2 years and type of intervention.)

†Mean (SD). Student $t$ test analysis for independent variables. 


\section{What is already known on this subject}

- Obesity has become an epidemic. Childhood obesity is considered a health risk and it reduces life expectancy.

- The educational interventions towards food and physical activity during childhood could be a key strategy in the prevention of obesity.

- Food habits are acquired during childhood especially under the age of 7 years. There are few studies in school children at this age and, in most, the intervention has proved ineffective.

\section{What this study adds}

- A school-based intervention, using investigation, vision, action and change methodology, in children of $6-8$ years, improves eating habits and increases physical activity.

- An educational intervention decreases weight excess in children.

- The decrease in weight excess does not depend on sex, previous body mass index or ethnical background.

- In children whose mothers have only primary schooling or less, the intervention has not been effective.

The intervention has resulted in a reduction in BMI progression, increase in fruit intake and an increase in physical activity. It has shown that it is possible to control the weight excess in children from interventions at school. Children felt supported by changes in the school environment and family involvement. Further studies are needed to assess if this educational intervention using the methodology IVAC during 2 years is effective in the long term or if a longer period of intervention would be needed.

Acknowledgements We thank Professor Carles Vallbona for excellent encouragement and advice. We thank the children and their parents for their participation and the schools for their cooperation.

Funding This study was supported by Observatori de la Salut Carles Vallbona, Fundació Hospital Asil de Granollers, Public Health Department, Granollers City Council, Primary Health Subdivision (PCS) Granollers-Mollet, Catalan Institute of Health and by Health Department, Generalitat de Catalunya, Spain.

Competing interests None declared.

Ethics approval This study was conducted with the approval of the Clinical Research Ethical Committee of Granollers General Hospital.

Provenance and peer review Not commissioned; externally peer reviewed.

\section{REFERENCES}

1. International Association for the Study of Obesity.org. London: International Association for the Study of Obesity. Global trends in childhood overweight, 2008 http://www.iaso.org/policy/trackingobesity/global-trends-childhood-overweight (accessed 8 Jul 2010).

2. Ebbeling CB, Pawlak DB, Ludwig DS. Childhood obesity: public-health crisis, common sense cure. Lancet 2002;360:473-82.
3. Kremer S, de Bruijn GJ, Visscher T, et al. Environmental influences on energy balance-related behaviour: a pragmatic approach to Explain and Influence Health Behaviours at the population level. Prev Med (Baltim) 2000;30:146-54.

4. Estrategia NAOS: Invertir la tendencia de la obesidad. Estrategia para la nutrición, actividad física y prevención de la obesidad. Madrid: Agencia española de Seguridad Alimentaria. Ministerio de Sanidad y Consumo, 2005.

5. Pla Integral per a la promoció de la salut mitjançant l'activitat física i l'alimentació saludable (PAAS). Barcelona: Departament de Salut. Generalitat de Catalunya, 2005

6. PERSEO programme. Madrid: Agencia Española de Seguridad Alimentaria y Nutrición. http://www.perseo.aesan.msps.es (accessed 1 Sep 2009).

7. Shape-up Europe Project. Barcelona: University of Hull, Schulen ans Netz e.V and PA.U. Education S.L., 2006. http://www.shapeupeurope.net/index.php?page=home (accessed 1 Sep 2009).

8. I Jornada Tècnica del PAAS (Promoció d'Activitat física i Alimentació Saludable). Barcelona: Generalitat de Catalunya, 2002. http://www.gencat.cat/ salut/depsalut/html/ca/dir2622/doc27549.html (accessed 1 Sep 2009).

9. Hill J0. Can a small-changes approach help address the obesity epidemic? A report of the Joint Task Force of the American Society for Nutrition, Institute of Food Technologists, and International Food Information Council. Am J Clin Nutr 2009:89:477-84.

10. Kropski JA, Keckley PH, Jensen GL. School-based obesity prevention programs: an evidence-based review. Obesity (Silver Spring) 2008;16:1009-18.

11. Brown T, Summerbell C. Systematic review of school-based interventions that focus on changing dietary intake and physical activity levels to prevent childhood obesity: an update to the obesity guidance produced by the national Institute for Health and clinical Excellence. Obes Rev 2009;10:110-41.

12. van Sluijs EM, McMinn AM, Griffin SJ. Effectiveness of interventions to promote physical activity in children and adolescents: systematic review of controlled trial. BMJ 2007;235:703-15

13. Shaya FT, Flores D, Gbarayor CM, et al. School-based obesity interventions: a literature review. J Sch Health 2008:78:186-96.

14. Müller MJ, Asbeck I, Mast M, et al. Prevention of obesity-more than an intention. Concept and first results odd the Kiel Obesity Prevention Study (KOPS). Int J Obes Relat Metab Disord 2001;25(Suppl 1):S66-74.

15. Nicklaus S. Development of food variety in children. Appetite 2009;52:253-5.

16. Serra LL, Aranceta J, Ribas L, et al. Crecimiento y desarrollo: dimensión alimentaria y nutricional. In: Serra LL, Aranceta J, Rodrígue-Santos J, eds. Crecimiento y desarrollo Estudio en Kid Krece Plus. Barcelona: Masson, 2003:45-55.

17. Simovska V, Jensen $B B$, et al. Per a un creixement sa i equilibrat. Nens i adults actuen junts. In: Shape Up, ed. Guia metodològica. Un enfocament escolar $i$ comunitari per influir en els determinants del creixement sa $i$ equilibrat. Barcelona: P.A.U. Education, 2006:18-24.

18. Cole TJ, Bellizzi MC, Flegal KM, et al. Establishing a Standard definition for child overweight and obesity worldwide: international survey. BMJ 2000;320:1240-3.

19. Adams G, Gulliford MC, Ukoumunne OC, et al. Patterns of intra-cluster correlation from primary care research to inform study design and analysis. J Clin Epidemiol 2004; 57:785-94.

20. Parker DR, Evangelou E, Eaton CB. Intraclass correlation coefficients for cluster randomized trials in primary care: the cholesterol education and research trial (CEART). Contemp Clin Trials 2005:26:260-7.

21. Ukoumunne OC, Gulliford MC, Chinn S, et al. Methods for evaluating area-wide and organisation-based interventions in health and health care: a systematic review. Health Technol Assess 1999;3:iii-92.

22. Ferrari P, Kaaks R, Fahey MT, et al; European Prospective Investigation into Cance and Nutrition study. Within- and between-cohort variation in measured macronutrient intakes, taking account of measurement errors, in the European Prospective Investigation into Cancer and Nutrition study. Am J Epidemiol 2004;160:814-22.

23. Ying Z, Gutin B, Johnson $\mathrm{MH}$, et al. An environmental approach to obesity prevention in children: Medical College of Georgia Fitkid Project year 1 results. Obes Res 2005; 13:2153-61.

24. Taylor RW, McAuley KA, Barbezat W, et al. APPLE Project: 2-y findings of a community-based obesity prevention program in primary school-age children. $A m \mathrm{~J}$ Clin Nutr 2007;86:735-42.

25. Sánchez M, Martínez V. Actividad física y prevención de la obesidad infantil. Intervención MOVI. In: de Castilla-La Mancha Universidad, ed. Ciudad Real: Universidad de Castilla-La Mancha, 2009:1-370.

26. Plachta-Danielzik S, Pust S, Asbeck I, et al. Four-year Follow-up of school-based Intervention on overweight children: The KOPS study. Obesity (Silver Spring) 2007:15:3159-69.

27. Deaton A. Height, health and development. Proc Natl Acad Sci U S A 2007; 104:13232-7

28. Suliga $\mathbf{E}$. Socio-economic differentiation of the growth and the dietary intake of Polish boys aged 7-16 years. Ann Hum Biol 2009;36:199-210. 